\title{
Searching Techniques in the Literature of the Sciences
}

\author{
By HUGH E. VORESS
}

THERE ARE MANY points to consider in making an effective science literature search. Initially, it is assumed that one must attempt to locate all available information relevant to a subject at the level required by the requester. With patents, all available information is required in order to establish priority in the recording of ideas and inventions. With the volume of literature now growing at an accelerating and unprecedented rate, retrieval is made more difficult by the sheer volume of information available. An effort to retrieve specific information concerning a specific subject or an effort to retrieve general information concerning a general subject must be carefully planned. Efficiency in literature searching can be gained only by experience, but certain principles which may be modified to suit the conditions of almost any particular situation can be set forth.

In order to perform a comprehensive examination of literature, the following steps should be taken:

1. Determine the subject scope

2. Determine the temporal scope

3. Determine the depth

4. Determine the literature to be used, e.g., abstract journals, handbooks, books, etc.

5. Familiarize oneself with the indexes to be used

6. Determine the subject headings involved

7. Scan the subject indexes

8. Check the abstracts cited in the indexes for pertinency

9. Prepare a list of authors of selected references
Mr. Voress is Chief of the Technical Literature Section, Division of Technical Information Extension, United States Atomic Energy Commission. This article was prepared from a talk given by $M r$. Voress at the Conference on the Literature of Nuclear Science: Its Management and Use, held at Oak Ridge, Tennessee, September 11-13, 1962.

10. Scan the author indexes for additional references

11. Prepare a list of corporate authors (issuing agencies)

12. Scan the corporate author indexes for additional references

13. Arrange all the references in the order desired

14. Edit the citations into the same format

15. Compose the finished copy.

\section{Exact Needs of the Requester}

The searcher must first determine the scope of the subject. In other words, he must determine "what the requester wants." Although a written statement should be obtained of his needs, it is frequently necessary to have several discussions with the requester in order that these needs might be understood clearly. Requesters may not know just what type of information will be helpful or available, or even what type of information they want. Such a discussion may help to formulate better the exact requirements. The requester should be asked if he has done any investigating himself in order to avoid duplication of effort. If he does not understand how to 
examine the reference tools he has already used, this work may have to be done again by a trained searcher.

The parameters or limits of the requester's needs often go beyond subject alone. It may be that only information developed after a certain date is sought. Or, he may want only that developed by a certain person, company, or in certain countries. Adding qualifications of this type will greatly reduce the amount of time and effort required for retrieval.

\section{Scope of the Requester's Needs}

The definition of the scope of the request should be explored from a subject standpoint so that all possible information related to the request will be considered. An experienced searcher examines textbooks, encyclopedias, and dictionaries to find related subjects of probable interest. No one, regardless of his subject specialties, can know all of these relationships. Discussion with a scientist or specialist in the field, other than the requester, often serves to determine whether any fields have been overlooked.

\section{SOURCES AND REFERENCE TOOLS TO BE UsED}

In making the search itself, the first step is to examine various guides to scientific literature in the reference section of the library for selection of the proper reference tools. Those offering the most promise should be chosen before work is begun. Use of such a publication as $\mathrm{Sci}$ ence Reference Sources by Frances Briggs Jenkins will assist in making this determination.

\section{Headings to Be Examined}

It is necessary in the case of abstract journal indexes to understand the particular method of indexing used. This is usually explained in the introduction to the index. The United States Atomic Energy Commission issues a publication entitled "Subject Headings Used by the Atomic Energy Commission," TID-5001, which provides such an explanation. Constituting the subject heading authority for Nuclear Science Abstracts, TID-5001 lists permissible headings that can be used by the indexer, and crossrefers to other related information. This publication has been distributed to all contractor and depository libraries.

Pertinent subject headings vary from one abstract journal to another, and it has been found helpful to list the subject headings selected for each journal. Revision of these lists becomes necessary as the work progresses and relationships are discovered that were not readily apparent at the outset.

\section{COMPREHENSIVENESS AND TIME PERIOD}

A fundamental decision that must be made is whether the investigation needs to be brief or comprehensive. Occasionally, a preliminary determination is made of the amount of literature that will have to be covered. This will permit the searcher to advise the requester of the probable time involved. In general, comprehensive subjects usually require months of work, and a requester should be advised of the probable cost in both time and effort. Just how comprehensive the review should be is only one facet of the problem; another concerns the span of time in months and years to be covered in the literature. A third consideration is the body of literature that should be covered, i.e., patents, periodicals, handbooks, books, monographs, bibliographies, reviews, encyclopedias, etc. Review articles, books, monographs, and bibliographies frequently summarize older information and thereby may reduce the necessity of reviewing some of the older literature. It is helpful to arrange these sources of information in order of importance; then, should expediency be 
a factor, the most important source can be checked first. Usually, the most recent sources are explored first.

\section{Evaluation of References AND Abstracts}

After an index has been searched, the cited abstracts must be read to determine whether they are pertinent. This is necessary because all people do not think alike, and methods of conveying information through indexes are often not consistent. Indexes cannot fully express the content of titles and abstracts. Should the information uncovered be of a particular nature, e.g., patents, scanning of publications specializing in patent literature may turn up additional references.

\section{Authors and Corporate Authors}

Another aid is to list the authors of the selected references. Examination of the author index in an abstract journal may result in the location of additional references that were not indexed. Sometimes an examination of the corporate authors or issuing agencies can also be fruitful. Work being performed at an installation may be subject-indexed by several different people over a period of time. This can result in variations in style, as a subject considered worthy of indexing by one person may not be considered so by another. A search of the corporate author index may give additional help in alleviating this problem.

\section{STYLing OF THE REFERENCES}

Editing of all references found into a single style is the next step. This is advisable because there are many individual styles used by the various abstracting services. Almost all abstract journals vary as to journal abbreviations in the citation. However, the same abbreviations should be used for references from a given journal source. In addition, some journals may list references by author, while others may cite by title.

\section{Termination of Search}

During styling and consolidation, if evaluation indicates that the information desired has been located, this phase may be terminated. However, location of only scanty amounts of information may indicate that a greater time span may be necessary or that a different body of literature should be surveyed. As mentioned before, the most important abstracting journals pertinent to the subject should be examined first, starting with the most recent issues. As one examines the older issues of an abstract journal, it is important to remember that there may be changes in nomenclature and terminology which will obviously affect subject headings.

\section{Presentation of References}

A final point to consider is the manner in which the information will be presented to the requester. Within the USAEC Division of Technical Information Extension, any literature search which has taken appreciable time or has resulted in a significant list of references is published in order to provide this material to others with similar needs. These publications are distributed both to the Atomic Energy Commission contractors and to the depository library collections. They are also cited in the TID3700 series of Informal Listing of Bibliographies of Atomic Energy Literature, which covers on a current basis bibliographies in preparation and completed. Bibliographies of Interest to the Atomic Energy Program, TID-3043 (Rev. 2), is a cumulation covering all bibliographies and literature searches through November 1961 and is supplemented on an annual basis. These documents are in the depository collections and should be kept in the reference section. The latest 
complete list of AEC depository libraries appears in current issues of Nuclear Science Abstracts.

\section{Summary}

The steps employed in searching the scientific and technical literature at the Division of Technical Information Extension, AEC, Oak Ridge, Tennessee, are described. Determinations must be made concerning the exact needs of the requester, the scope of the subject area in question, the sources and reference tools most likely to be productive, subject headings to be examined, and the time period to be covered. Necessity for evaluation of the references and abstracts located, additional searching of author indexes, and final selection, styling, and presentation of references are discussed. Criteria for terminating searches are shown to vary according to the conditions of the individual search.

\section{Argonne National Laboratory Tour}

ACRL Subject Specialist Section-RSD Information Retrieval Committee-Interdivisional Committee on Documentation are sponsoring a tour of the library and information services of the Argonne National Laboratory on Friday afternoon, July 19, during the Chicago conference of ALA.

Buses will leave the Hilton Hotel at 1:30 P.M. and will return passengers to the hotel at 6:00 P.M. Cost for transportation will be $\$ 1.50$ per person.

The tour will include the library and information resources, plus some of the facilities such as a nuclear reactor of the Argonne National Laboratory, and the Applied Math division where computer use in library procedures will be demonstrated. Tickets for the tour will be available at the conference Tours desk.

\section{Grant for Columbia Operations Analysis}

A GRANT of $\$ 7,200$ has been made by the council on Library Resources to Columbia University to assist the university libraries in an operations analysis, looking toward improvement of administration. The investigation will have the assistance of some nonlibrary university staff and facilities, including computers if needed. The investigation will seek to identify the major activities of research library operation, the kinds and levels of skills of competency involved in each activity, mental versus manual processes - all this in relation to other activities and to the operation as a whole-and what may be gained or lost if changes are made in these activities. 